\title{
DERLEMIE / REVIEW
}

Balıkesir Sağlık Bilimleri Dergisi / BAUN Sağ Bil Derg

Balıkesir Health Sciences Journal / BAUN Health Sci J

ISSN: 2146-9601- e ISSN: 2147-2238

Doi: https://doi.org/10.53424/balikesirsbd.882071

\section{Multiple Skleroz ve Mikrobiyata}

\section{Tuba BAYDAN 國, Sibel KARACA SIVRIKKAYA ${ }^{2}$}

${ }^{1}$ İzmir Sağlık Bilimleri Üniversitesi, Tepecik Eğitim ve Araştırma Hastanesi

${ }^{2}$ Balıkesir Üniversitesi, Sağlık Bilimleri Fakültesi, Hemşirelik Bölümü

Geliş Tarihi / Received: 17.02.2020, Kabul Tarihi / Accepted: 26.05.2021

\section{ÖZ}

İntestinal mikrobiyotanın son yıllarda yapılan çalışmalarında insan sağlığı ve hastalığı üzerinde etkili olduğu görülmüş, Multiple Skleroz (MS) dahil birçok hastalıkla ilişkisinin bulunması sebebiyle, intestinal mikrobiyotanın kișiler üzerindeki etkisine odaklanılmıştır. MS 20-40 yaşları arasında genç yetişkinlikte görülen, kadınların daha fazla risk altında olduğu, tekrarlayıcı nörolojik fonksiyon bozuklukları ile seyreden kronik bir hastalıktır. Yapılan çalışmalarda bağırsak mikrobiyotasındaki hemostazın bozulmasının Merkezi Sinir Sisteminde (MSS) değişikliklere yol açtığı ve çeşitli MSS hastalıklarının ilerlemesine sebep olduğu bildirilmiştir. Bireylerin sağlıklarının geliştirilmesi, sürdürülmesi ve hastalıklardan korunmasında hemşirelerin büyük rolü bulunmaktadır. Hemşireler mikrobik toplulukların temel yapı ve işlevlerini bilmeli, güncel yaklaşımlara ilişsin bilgilerini arttırmalı ve geliştirdiği bilgi ve becerilerini bakımlarına yansıtabilmelidir. İntestinal mikrobiyotanın MS'e etkisinin mevcut araştırmalara ek araştırmalarla desteklenmesi ve farkındalığının arttırılması, hastalıklardan korunma stratejilerinin geliştirilmesinde önemli bir adım olacaktır. Yapılacak çalışmalarla, intestinal mikrobiyotanın düzenlenmesinde, MS'e ilişkin geliştirilen stratejilerin kullanılmasıyla risk altındaki bireylerin MS'den korunmasının mümkün olacağı öngörülmektedir.

Anahtar Kelimeler: Multiple Skleroz, İntestinal Mikrobiyota, Bağırsak-Beyin Aksı.

\begin{abstract}
Recent studies have focused on the effect of intestinal microbiota on individuals, since intestinal microbiota has an impact on human health and disease, and is associated with many diseases, including Multiple Sclerosis (MS). MS is a chronic disease seen in young adulthood between the ages of 20-40, where women are at greater risk and with repetitive neurological dysfunctions. In the studies, deterioration of hemostasis in the intestinal microbiota leads to changes in the Central Nervous System (CNS) and has been reported to cause the progression of various CNS diseases. Nurses have a great role in improving and maintaining the health of individuals and protecting them from diseases. Nurses should increase their knowledge of current approaches, know the basic functions and structure of microbial communities and be able to reflect their knowledge and skills to their care. Promoting the effect of intestinal microbiota on MS with additional research and raising awareness will be an important step in developing disease prevention strategies. With the studies to be done, it is anticipated that it is possible to protect at-risk individuals from MS by using strategies developed for MS in the regulation of intestinal microbiota.
\end{abstract}

Multiple Sclerosis and Microbiota

Keywords: Multiple Sclerosis, Intestinal Microbiota, Intestinal-Brain Axis.

Sorumlu Yazar / Corresponding Author: Tuba BAYDAN, İzmir Sağlık Bilimleri Üniversitesi, Tepecik Eğitim ve Araştırma Hastanesi İzmir, Türkiye

E-mail: tubabaydan@ outlook.com

Bu makaleye atıf yapmak için / Cite this article: Baydan, T., \& Karaca Sivrikaya, S. (2021). Multiple Skleroz ve mikrobiyata. Balıkesir Sağlık Bilimleri Dergisi, 10(3):410-415. https://doi.org/10.53424/balikesirsbd.882071

CCopyright 2021 by the Balıkesir Sağlık Bilimleri Dergisi.

BAUN Să̆ Bil Derg 2021 OPEN ACCESS https://dergipark.org.tr/tr/pub/balikesirsbd

This work is licensed under a Creative Commons Attribution-NonCommercial 4.0 International License 


\section{GiRIŞ}

Multiple Skleroz (MS), merkezi sinir sistemi (MSS) miyelinin prototipik hastalığıdır (Hauser, Chan ve Oksenberg, 2013). Lipit açısından zengin bir membran olan miyelin, aynı zamanda impuls iletimini hızlandıran çok katmanlı bir yalıtım proteinidir (Hauser, Oksenberg ve Baranzini, 2015). Tekrarlayıcı nörolojik fonksiyon bozuklukları ile seyreden, aynı zamanda ilerleyici ve kronik bir hastalık olan MS genel olarak 20-40 yaş arasındaki bireylerin sağlığını tehdit eden, büyük oranda iş gücü kaybı ve önemli engellere sebep olan MSS'nin kronik enflamatuvar bir hastalığıdır (Dayapoğlu, Tan ve Dayapoğlu, 2011; Yamout ve Alroughani, 2018). MS insidans ve prevalansı, gelişmiş ve gelişmekte olan ülkelerde artmaktadır. Ancak bu artışın altındaki sebep bilinmemektedir (Dobson ve Giovannoni, 2019). MS hastalarında; \%80 oranında mesane fonksiyon bozukluğu görülürken, \%50-90 oranında yorgunluk tespit edilmiştir. MS hastası kadınların \%72'sinin cinsel fonksiyonlarının etkilendiği saptanırken erkeklerde bu oran \%91'dir (Dilek, Bitek, Özgül ve Ünsar, 2019). Etiyolojisi tam olarak bilinmeyen MS hastalığının ortaya çıkmasında genetik ve çevresel faktörlerin etkili olduğu düşünülmektedir (Katsara ve Apostolopoulos, 2018). Sigara kullanımı, düşük $\mathrm{D}$ vitamini düzeyi gibi faktörlerin MS oluşumu riskini arttırdığ 1 saptanmıştır (Zahoor ve Haq, 2017). Balık tüketiminin arttrrılması, Omega 3'ten zengin beslenmede hastalıkta olumludur ancak kesin kanıtlar mevcut değildir (Demir ve Yıldız, 2015). MS oluşumunda etkili diğer bir faktör de mikrobiyotadır. İnsan vücudundaki mikroorganizma sayısı, toplam insan hücre sayısından 10 kat fazladır. $\mathrm{Bu}$ mikroorganizmaların büyük bir kısmını bakteriler oluşturmaktadır. Funguslar, ökaryotik mikroorganizmalar ve virüsler de insan mikrobiyotasında yer almaktadır (Uygun, 2017). Bağırsak mikrobiyotası bağırsak ve beyin arasında karşılıklı bir ilişki oluşturarak insan sağlığ üzerinde önemli ve temel bir rol oynamaktadır (Evrensel ve Ceylan, 2015). Beyin ve bağırsak, çift yönlü sinir, bağışıklık ve endokrin iletişimi yoluyla bağırsak-beyin eksenini oluşturmaktadır. Böylelikle organlardan birinde oluşan değişiklikler diğer organları da etkilemektedir. Bağırsak mikroorganizmalarının miktarındaki ve bileşimindeki bozukluklar MSS'ye etki etmekte ve bu da mikrobiyota-bağırsak-beyin ekseninin varlığını göstermektedir. Beyin ve bağırsak arasındaki karmaşık etkileşimler sebebiyle, bağırsak mikrobiyotası, Parkinson, şizofreni, MS ve Alzheimer hastalığ 1 gibi çeşitli MSS hastalıkları ile yakından ilişkilendirilmektedir (Zhu ve ark., 2017). Bu derlemede, MS hastalı̆̆ı, epidemiyolojisi, risk faktörleri, mikrobiyota ve MS' in mikrobiyata ile ilişkisi ve hemşirelikten bahsedilecektir.

\section{Multiple Skleroz ve epidemiyolojisi}

İlk olarak 1838 yılında tanımlanan MS, 20. yy'ın başlarında nörolojide en sık görülen hastalıklardan biri olmuştur (Öztürk, Aytaç, Kızılay ve Sindel, 2017).

Şekil 1'de görüldüğü gibi MS, genç yetişkinlik olarak adlandırılan 20-40 yaşları arasında görülmektedir; kadınlar erkeklerden iki üç kat daha fazla risk altındadır ve bu durum dünyanın bazı bölgelerinde daha da artmaktadır (Amato ve ark., 2018). Global medyan MS prevalansı 100.000 kişi başına 33'tür ve ülkeler arasında önemli farkll1ıklar göstermektedir (Oh, Vidal-Jordana ve Montalban, 2018). Günümüzde 2,3 milyon MS hastas1 olduğu tahmin edilmektedir (Schiess ve Calabresi, 2016). Türkiye'de yaklaşı 50.000 MS hastası olduğu tahmin edilmektedir. Bu kişilerin de \%35'inin erkek \%65'inin kadın olduğu bilinmektedir (Börü ve ark., 2018).

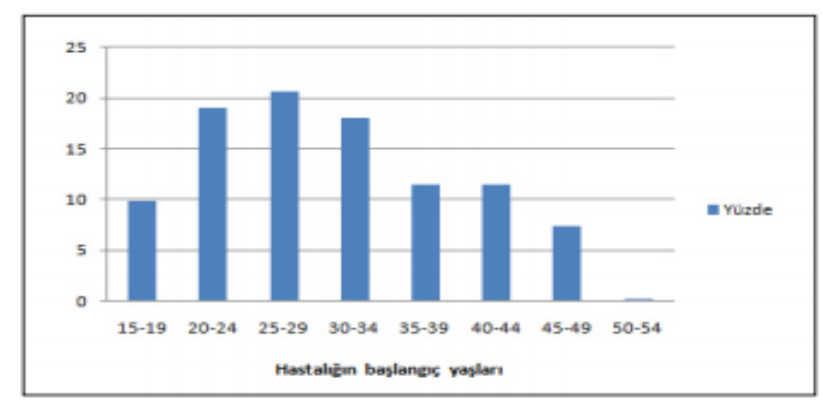

\section{Şekil 1. MS hastalığının, hastaların başlangıç yaşlarına göre dağılma yüzdeleri (Öztürk ve ark., 2017).}

\section{MULTIPLE SKLEROZ HASTALIĞININ RISK FAKTÖRLERI}

MS'in etiyolojisi tam olarak bilinmemekle birlikte, genetik ve çevresel faktörlerin tetiklediği, bağışıklık sisteminin demiyelinizasyonundan kaynaklandığına inanılmaktadır (Ascherio ve Munger, 2007).

MS kalıtsal bir hastalık olmamasına rağmen etiyolojisinde genetik bileşenler çok güçlüdür. MS hastalarının birinci derece akrabaları arasında MS riski genel popülasyondan 10-50 kat daha fazladır (Garg ve Smith, 2015).

MS gelişmesinde rol oynayan bir diğer faktör ise; bağırsak florasıdır. Sürekli olarak bir dizi mikrobiyolojik ve immünolojik faktörlere maruz kalan bağırsak florasının geçirgenliği ihlal edildiğinde komensal bakteriler ve istenmeyen büyük moleküller mukoza zarına girmektedir. $\mathrm{Bu}$ durum mikrobiyotanın bozulmasına ve MS riskinin artmasina sebep olabilmektedir (Odenwald ve Turner, 2017).

\section{MIKKROBIYOTA}

Mikroorganizmalar 3,8 milyon yıldır biyosferde varlıklarını sürdürmektedirler. İnsanlar ise biyosferi 10 bin yıldır etkilemektedir. Bunun yanında iç biyosfer yani mikrobiyota da etkilenmektedir (Yılmaz ve Altındiş, 2017). Her organda, diğer adı flora olan mikrobiyota bulunmaktadır. Mikrobiyota denildiğinde akla ilk olarak gastrointestinal sistem gelmektedir. Bağırsak mikrobiyotasındaki mikroorganizmalar, insan fizyolojisinin sürdürülmesinde, biçimlendirilmesinde ve homeostazında aktif olarak rol almaktadır (Kalip \& Atak, 2018). Mikrobiyotanın büyük bir kısmını bakterilerin bağırsak hattı boyunca kurduğu koloniler oluşturmaktadır. Bunun yanında ökaryotik, virüsler, fungi ve az sayıda arke de bulunmaktadır (Biedermann ve Rogler, 2015). 
Mikrobiyota insanlarla beraber yaşayan özel türlerin tamamını ifade etmektedir (Xu ve Knight, 2015). Mikrobiyotanın insanda sağlık ve hastalık durumlarında önemli rolü bulunmaktadır. Başta intestinal mikrobiyota olmak üzere mikrobiyota insanda sağlık ve hastalık durumlarını, bağışıklık sistem fonksiyonlarının normal gelişimini ve bağışıklı sistemi hücrelerinin olgunlaşmasını teşvik etmek için gerekli sinyalleri sağlayarak düzenlemektedir (Chow, Lee, Shen, Khosravi ve Mazmanian, 2010). Bağırsak florası, sindirim sistemi mukozasında yaşayan konak organizmanın başta sindirim olmak üzere çeşitli fonksiyonlarında önemli işlevleri olan mikroorganizma topluluğudur (Çiplak ve ark., 2019). Bağırsak florası parmak izi gibidir, her insanın bağırsak florası çeşitli faktörlerden etkilenerek kendine özgü içerik ve dağılım gösterir. Tek yumurta ikizlerinin dahi bağırsak floraları birbirinden farklıdır (Yüksel Altuntaş \& Batman, 2017). Mideden kalın bağırsağa doğru gidildikçe bakteri çeşitliliği ve sayısı büyük oranda artmaktadır. Sağlıklı bir insanın bağırsak florasındaki bakterilerin \%98'i faydalıdır ve insanlar ile bağırsak mikrobiyotası arasında simbiyotik bir ilişki bulunmaktadır (Genç ve Zorba, 2019). Bağırsaklarda 100-150 trilyon canlı bakteri bulunmaktadır. $\mathrm{Bu}$ canlı bakteriler insanda bağırsak florasını oluşturarak; bağışıklık sistemi, sindirim sistemi fonksiyonları, serotonin hormonu, nörotransmitter madde üretimi, bazı vitaminlerin emilim ve sentezi gibi çeşitli fizyolojik süreçlere katkı sağlamaktadır (Bressa ve ark., 2017). Eksojen ve endojen faktörlerden etkilenen mikrobiyota gebelik döneminden itibaren farklılaşmaya başlamakta ve antibiyotik, stres, beslenme biçimi, alkol, sigara ve sedanter yaşam tarzı bağırsak florasında değişime sebep olmaktadır. Mikrobiyotanın bozulması bağırsak duvarını tahrip etmekte ve bağırsak geçirgenliğini arttırmaktadır (Kalip ve Atak, 2018). Bu bireylerin bağışıklık sistemi zayıflamakta ve kalp, dolaşım sistemi, depresyon, otoimmün hastalıklar, MS, Alzheimer, Parkinson gibi hastalıklar gelişerek yaşam kalitesini olumsuz etkilemektedir (Genç ve Zorba, 2019).

\section{MULTIPLE SKLEROZ HASTALIĞI VE MÍKROBIYYOTA İLISKISİ}

"Bağırsak-beyin ekseni" kavramı bağırsak mikrobiyotasının ve metabolitlerinin, immünolojik sinyalleme yoluyla MSS'deki farklı hücresel bileşenlerle doğrudan ve dolaylı etkileşimini içermektedir. Bağırsak mikrobiyotasındaki hemostazın bozulması, MSS'de değişikliklere yol açmakta ve çeşitli MSS hastalıklarının ilerlemesine sebep olmaktadır (Ma ve ark., 2019).

Bağırsaktaki mikrobiyotanın dengesinin bozulması, mikrobiyota kompozisyonunun değişmesi ve bu durumlara bağlı olarak bağırsak bariyerinin bozulma durumu MS gibi kronik enflamatuvar hastalıkların gelişimine zemin hazırlamaktadır (Sekirov, Russell, Antunes ve Finlay, 2010).

Tüm yaşayan mikroorganizmaların gastrointestinal sistemdeki birleşimi olarak tanımlanan bağırsak mikrobiyotasının, beyin gelişimi üzerindeki etkisi son y1llarda ilgi odağı olmuştur (Khanna ve Tosh, 2014). Bağırsak mikrobiyotası bağışıklık sistemi ve epitel hücreleriyle iletişim içinde olduğu için başta otoimmün hastalıklar olmak üzere metabolik ve nöropsikiyatrik hastalıklar gibi pek çok hastalığın oluşmasında rolü olduğu düşünülmektedir (Borre ve ark., 2014). Mikribiyota, gastrointestinal ekosisteminde bulunan ve değişikliği yalnızca bağırsak bozukluklarını değil aynı zamanda MS gibi MSS bozukluklarını da etkileyen karmaşık bir mikroorganizma türünü içermektedir (Jiang, Li, Huang, Liu ve Zhao, 2017).

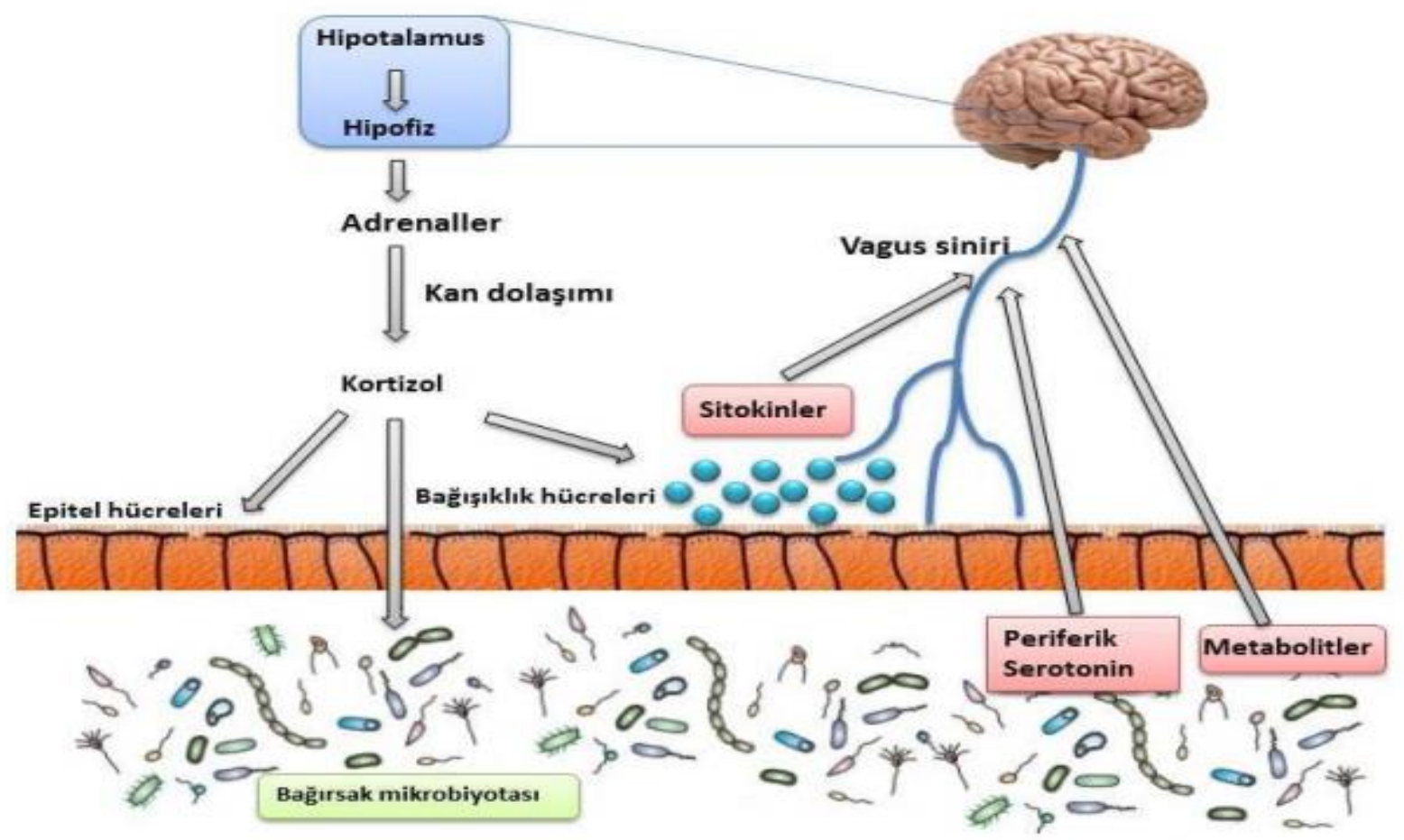

Şekil 2. Bağırsak mikrobiyotası ve beyin arasındaki etkileşim (Sugeçti, Büyükgüzel, \& Büyükgüzel, 2019). 
Periferik serotonin: bağırsaktaki hücreler beyin sinyal mekanizmasında etkili serotonin üretmektedirler. Sitokinler: bağırsak mikrobiyotası, bağışıklık hücrelerinin sitokin üretmesini tetikler. Metabolitler: mikroorganizmalar, beyni doğrudan etkileyebilen metabolitler üretebilmektedirler (Şekil 2) (Sugeçti ve ark., 2019).

Bağırsak lümeni içerisindeki mikrobiyotalar birçok biyokimyasal reaksiyon gerçekleştirmektedir $\mathrm{Bu}$ reaksiyonlar sonucunda oluşan biyokimyasal moleküller bağırsak reseptörlerine bağlanarak birçok fizyolojik değişikliğe sebep olabilmektedirler (Barrett, Ross, O'Toole, Fitzgerald ve Stanton, 2012). Bu biyokimyasal maddeler: antioksidan metabolizmanın azalmasına sebep olarak hücrelerde oksidatif hasar oluşturabilmektedir. Oksidatif hasar sinirsel aktivasyon moleküllerini doğrudan etkileyebilmektedir (Sugeçti ve ark., 2019). Sinyal aktivasyonu için kullanılan birçok biyomolekülün (histamin, serotonin, melatonin vb.) bağırsak ve beyin arasındaki fizyolojik etkileşiminde rolü bulunmaktadır (Mandal, Saha, ve Das, 2015). Ayrıca bağırsak mikrobiyotası beyinde hafıza ve öğrenme merkezini, nörogenezisi ve nörotransmitter üretimini etkileyerek birçok nörolojik hastalıkların gelişimine sebep olabilmektedir. Özellikle Alzheimer, MS ve Parkinson gibi nörolojik hastalıkların tetiklenmesinde oldukça önemlidir (Luczynski ve ark., 2016).

Bağırsak mikrobiyotası, bağırsak bariyerinin sağlam bir şekilde korunması, bağışıklık yanıtlarının ve konakçı fizyolojisinin düzenlenmesi, patojenik organizmalar tarafından kolonizasyonun engellenmesi dahil birçok şekilde sağlıklı durumun korunmasına yardımcı olmaktadır (Zhang, Hornef ve Dupont, 2015).

Yapılan çalışmalar sonucunda MS görülen bireylerde, sağlıklı bireylere göre daha farklı bağırsak bakterisi görüldüğü saptanmıştır. Bağırsak bakterilerindeki bu farklılı sindirim sisteminin yapısını bozmakta ve bağırsak geçirgenliğini etkilemektedir. Bağırsak geçirgenliği etkilenince tam olarak sindirilemeyen besinler bağırsak duvarından emilmeye çalışılmaktadır. Fakat tam anlamıyla parçalanamayan besinler, bağırsak duvarında yabancı kabul edilerek antikor oluşumuna sebep olmaktadır. Bu süreçte otoimmün hastalıklara ve dolayısıyla MS'e yol açmaktadır (Ochoa-Repáraz, Kirby ve Kasper, 2018).

\section{MIKKROBIYOTA VE HEMŞIRELIK}

Mikrobiyotanın düzenlenerek MS gelişiminin önlenmesinde hemşirelere önemli ve büyük roller düşmektedir, riskli bireylerin belirlenmesi, risk faktörlerinin azaltılması ve bireylerin duygu durumlarının, yaşam şekillerinin değerlendirilip, düzenlenerek sürdürülmesini sağlamaları gerekmektedir (McElroy, Chung, ve Regan, 2017). Bu süreçte ulaşabileceği her bireye ulaşmaları, bireylerin sağlıklı beslenmeleri konusunda diyetisyenle işbirliği içerisinde doğru ve tutarlı bilgilendirilmelerini sağlamaları, sağlığ teşvik edici uygulamaları planlamaları ve tüm bu adımları güncel kanıt ve sağlık standartlarına uygun olarak gerçekleştirmeleri, kişilerin sağlığının geliştirilmesi ve hastalıkların önlenmesi için dikkat edilmesi gereken önemli adımlar olacaktır (Patience, 2016). Mikrobiyota doğumdan ölüme kadar değişkenlik gösteren dinamik bir yapıdır. Hemşireler mevcut ve gelecekteki sağlığı koruyabilmek için her yaştaki bireylere bütüncül ve bireye özgü bakım vermelidir. Bireyleri özellikle hijyene dikkat etmeleri ve beslenme açısından uygun koşullarda hazırlanan gıdaların, peynir, yoğurt, kefir gibi probiyotikler ile sebze, meyve, lifli gidalar gibi prebiyotiklerin tüketilmesi konusunda diyetisyenle multidisipliner bir şekilde bilgilendirilmesi yapılmalıdır (Mozaffarian ve ark., 2015).

\section{SONUÇ}

Sağlık ve hastalık süreçlerinde bağırsak mikrobiyotasının konak üzerindeki etkileşimi son yıllarda üzerinde çok fazla durulan bir konudur. Bağırsak mikrobiyotasının miktar ve bileşimindeki bozukluklar MSS'ni etkileyebilmektedir. Bağırsak ve beyin arasındaki bu iki yönlü etkileşim MS gibi nörolojik hastalıkların oluşmasında rol oynamaktadır.

Bağırsak ve beyin arasında hormonlar ve nöral bağlantılar sayesinde güçlü ve çift yönlü bir iletişim mevcuttur. Bu aksdaki herhangi bir değişiklik, bu iki-etkileşimli sistemde fonksiyonel bozukluklara yol açabilmektedir. Günümüzde sahip olunan bilgilere ve kullanılan teknolojilere bakıldığında mikrobiyota ve MS arasındaki ilişkiyi açıklayan çalışmalar kısıtlıdır. Ancak bu konudaki çalışmaların gelecekte sağlayacağı firsatlar ve sunacağ terapötik olanaklar sebebiyle hızlı bir şekilde artacağı ve yaygınlaşacağı düşünülmektedir. Mikroorganizmalar, bağırsak-beyin-mikrobiyota ekseni ile MSS'nin işlevini ve gelişsimini etkilemektedir. Birçok MSS hastalığının mekanizması hala belirsizdir ve bu karmaşık ilişkinin keşfedilmesi MSS hastalıklarının incelenmesi için yeni bir araştırma yönü sağlayacaktır. Dünya'da Mikrobiyota üzerinde araştırmalar hız kesmeden devam ederken ülkemizde mikrobiyota üzerine çalışma yok denecek kadar azdır. Ülkemizde mikrobiyota konusu, mikrobiyotanın hastalıklarla olan ilişkisi daha sık ele alınması ve çalışmalar arttırılmalıdır.

\section{Çıkar Çatışması}

Yazarlar, bu makalenin araştırılması, yazarlı̆̆ 1 ve/veya yayınlanması ile ilgili olarak herhangi bir potansiyel çıkar çatışması beyan etmemiştir.

Yazar katkıları TB, SKS; Gereç, yöntem ve veri toplama: TB, SKS; Analiz ve yorum: TB, SKS; Yazım ve eleştirel değerlendirme: $\mathrm{TB}, \mathrm{SKS}$.

\section{KAYNAKLAR}

Amato, M. P., Derfuss, T., Hemmer, B., Liblau, R., Montalban, X., Soelberg Sørensen, P., \& Miller, D. H. (2018). Environmental modifiable risk factors for multiple sclerosis: Report from the 2016 ECTRIMS focused workshop. Multiple Sclerosis, 24(5), 590-603. http://doi.org/10.1177/1352458516686847

Ascherio, A., \& Munger, K. L. (2007). Environmental risk factors for multiple sclerosis. Part I: the role of infection. Annals of Neurology, 61(4), 288-299. http://doi.org/10.1002/ana.21117 
Barrett, E., Ross, R. P., O'Toole, P. W., Fitzgerald, G. F., \& Stanton, C. (2012). $\gamma$-Aminobutyric acid production by culturable bacteria from the human intestine. Journal of Applied Microbiology, 113(2), 411-417. http://doi.org/10.1111/j.1365-2672.2012.05344.x

Biedermann, L., \& Rogler, G. (2015). The intestinal microbiota: its role in health and disease. European Journal of Pediatrics, 174(2), 151-167. http://doi.org/10.1007/s00431-014-2476-2

Borre, Y. E., O'Keeffe, G. W., Clarke, G., Stanton, C., Dinan, T. G., \& Cryan, J. F. (2014). Microbiota and neurodevelopmental windows: implications for brain disorders. Trends in Molecular Medicine, 20(9), 509518. http://doi.org/10.1016/j.molmed.2014.05.002

Börü Ü, T., Bilgiç, A. B., Köseoğlu Toksoy, C., Yılmaz, A. Y., Tasdemir, M., Sensöz, N. P., . . . Bölük, C. (2018). Prevalence of Multiple Sclerosis in a Turkish City Bordering an Iron and Steel Factory. J Clin Neurol, 14(2), 234-241. http://doi.org/10.3988/jen.2018.14.2.234

Bressa, C., Bailén-Andrino, M., Pérez-Santiago, J., GonzálezSoltero, R., Pérez, M., Montalvo-Lominchar, M. G.,. Larrosa, M. (2017). Differences in gut microbiota profile between women with active lifestyle and sedentary women. PLoS One, 12(2), e0171352. http://doi.org/10.1371/journal.pone.0171352

Chow, J., Lee, S. M., Shen, Y., Khosravi, A., \& Mazmanian, S. K. (2010). Host-bacterial symbiosis in health and disease. Advances in Immunology, 107, 243-274. http://doi.org/10.1016/b978-0-12-381300-8.00008-3

Çiplak, M. E., Genç, A., Bïlïcï, M. F., Güder, F., Acar, H., \& Tutkun, E. (2019). Roseburia species in intestinal flora in amateur and professional male football players.

Dayapoğlu, N., Tan, M., \& Dayapoğlu, N. (2011). Multiple Sklerozlu Hastalarda Yorgunluk ve Hemşirelik Bakımı. Florence Nightingale Hemşirelik Dergisi, 19(2), 105-108.

Demir, A., \& Y1ldız, E. (2015). Multiple Skleroz ve Beslenme. Ortadogu Medical Journal, 7(3),66-70.

Dilek, F., Bitek, D. E., Özgül, E., \& Ünsar, S. (2019). Multiple Skleroz'da Üç Semptom ve Hemşirelik Yönetimi: Yorgunluk, Mesane Problemleri, Cinsellik. Anadolu Hemșirelik ve Sağlık Bilimleri Dergisi, 22(4), 300305.

Dobson, R., \& Giovannoni, G. (2019). Multiple sclerosis - a review. European Journal of Neurology, 26(1), 27-40. http://doi.org/10.1111/ene.13819

Evrensel, A., \& Ceylan, M. E. (2015). Bağırsak Beyin Ekseni: Psikiyatrik Bozukluklarda Bağırsak Mikrobiyotasının Rolü. Current Approaches in Psychiatry, 7(4), 461472

Garg, N., \& Smith, T. W. (2015). An update on immunopathogenesis, diagnosis, and treatment of multiple sclerosis. Brain and Behavior, 5(9), e00362. http://doi.org/10.1002/brb3.362

Genç, A., \& Zorba, E. (2019). Gizli Kahraman: Bağırsak Florası ve Egzersiz. 2. Uluslararasi herkes için spor ve wellness kongresi, p 953.

Hauser, S. L., Chan, J. R., \& Oksenberg, J. R. (2013). Multiple sclerosis: Prospects and promise. Annals of neurology, 74(3), 317-327. http://doi.org/10.1002/ana.24009

Hauser, S. L., Oksenberg, J. R., \& Baranzini, S. E. (2015). Chapter 85 - Multiple Sclerosis. In R. N. Rosenberg \& J. M. Pascual (Eds.), Rosenberg's Molecular and Genetic Basis of Neurological and Psychiatric
Disease (Fifth Edition) (pp. 1001-1014). Boston: Academic Press.

Jiang, C., Li, G., Huang, P., Liu, Z., \& Zhao, B. (2017). The Gut Microbiota and Alzheimer's Disease. Journal of Alzheimer's Disease, 58(1), 1-15. http://doi.org/10.3233/jad-161141

Kalip, K., \& Atak, N. (2018). Bağırsak mikrobiyotası ve sağlık. Turkish Journal of Public Health, 16(1), 58.

Katsara, M., \& Apostolopoulos, V. (2018). Editorial: Multiple Sclerosis: Pathogenesis and Therapeutics. Journal of Medicinal Chemistry, 14(2), 104-105. http://doi.org/10.2174/157340641402180206092504

Khanna, S., \& Tosh, P. K. (2014). A clinician's primer on the role of the microbiome in human health and disease. Mayo Clinic Proceedings, 89(1), 107-114. d http://doi.org/10.1016/j.mayocp.2013.10.011

Luczynski, P., McVey Neufeld, K. A., Oriach, C. S., Clarke, G., Dinan, T. G., \& Cryan, J. F. (2016). Growing up in a Bubble: Using Germ-Free Animals to Assess the Influence of the Gut Microbiota on Brain and Behavior. International Journal of Neuropsychopharmacology, 19(8). http://doi.org/10.1093/ijnp/pyw020

Ma, Q., Xing, C., Long, W., Wang, H. Y., Liu, Q., \& Wang, R. F. (2019). Impact of microbiota on central nervous system and neurological diseases: the gut-brain axis. $J$ Neuroinflammation, 16(1), 53. http://doi.org/10.1186/s12974-019-1434-3

Mandal, R. S., Saha, S., \& Das, S. (2015). Metagenomic surveys of gut microbiota. Genomics Proteomics Bioinformatics, $\quad 13(3), \quad 148-158$. http://doi.org/10.1016/j.gpb.2015.02.005

McElroy, K. G., Chung, S. Y., \& Regan, M. (2017). CE: Health and the Human Microbiome: A Primer for Nurses. American Journal of Nursing, 117(7), 24-30. http://doi.org/10.1097/01.naj.0000520917.73358.99

Mozaffarian, D., Benjamin, E. J., Go, A. S., Arnett, D. K., Blaha, M. J., Cushman, M., . . Turner, M. B. (2015). Heart disease and stroke statistics--2015 update: a report from the American Heart Association. Circulation, 131(4), e29-322. http://doi.org/10.1161/cir.0000000000000152

Ochoa-Repáraz, J., Kirby, T. O., \& Kasper, L. H. (2018). The Gut Microbiome and Multiple Sclerosis. Cold Spring Harb Perspect Med, 8(6). doi:10.1101/cshperspect.a029017

Odenwald, M. A., \& Turner, J. R. (2017). The intestinal epithelial barrier: a therapeutic target? Nature Reviews Gastroenterology \& Hepatology, 14(1), 9-21. http://doi.org/10.1038/nrgastro.2016.169

Oh, J., Vidal-Jordana, A., \& Montalban, X. (2018). Multiple sclerosis: clinical aspects. Current Opinion in Neurology, 31(6), 752-759. doi:10.1097/wco.0000000000000622

Öztürk, S., Aytaç, G., Kızılay, F., \& Sindel, M. (2017). Multipl Skleroz Multiple Sclerosis. Akdeniz Tip Dergisi, 3, 137-147.

Patience, S. (2016). Advising patients on nutrition and healthy eating. British Journal of Nursing, 25(21), 1182-1186. http://doi.org/10.12968/bjon.2016.25.21.1182

Schiess, N., \& Calabresi, P. A. (2016). Multiple Sclerosis. Semin Neurol, 36(4), 350-356. doi:10.1055/s-00361585456

Sekirov, I., Russell, S. L., Antunes, L. C., \& Finlay, B. B. (2010). Gut microbiota in health and disease. Physiological Reviews, 90(3), 859-904. doi:10.1152/physrev.00045.2009 
Sugeçti, S., Büyükgüzel, E., \& Büyükgüzel, K. (2019). Pathophysiologic Role of Intestinal Microbiota on Neurodegenerative Diseases. Journal of Immunology.

Uygun, A. (2017). Fekal Mikrobiyota Transplantasyonu (FMT). Journal of Biotechnology and Strategic Health Research, 1, 132-140.

Xu, Z., \& Knight, R. (2015). Dietary effects on human gut microbiome diversity. British Journal of Nutrition, 113 Suppl(Suppl 0), p1-5.

http://doi.org/10.1017/s0007114514004127

Yamout, B. I., \& Alroughani, R. (2018). Multiple Sclerosis. Seminars in Neurology, 38(2), 212-225. http://doi.org/10.1055/s-0038-1649502

Yılmaz, K., \& Altındiş, M. (2017). Sindirim sistemi mikrobiyotasi ve fekal transplantasyon. Nobel Medicus, 13(1), 9-15.

Yüksel Altuntaş, D., \& Batman, A. (2017). Mikrobiyota ve metabolik sendrom. Türk Kardiyoloji Derneği Arşivi, 45(3), 286-296.

Zahoor, I., \& Haq, E. (2017). Vitamin D and Multiple Sclerosis: An Update. In I. S. Zagon \& P. J. McLaughlin (Eds.), Multiple Sclerosis: Perspectives in Treatment and Pathogenesis. Brisbane (AU): Codon Publications

Copyright: The Authors.

Zhang, K., Hornef, M. W., \& Dupont, A. (2015). The intestinal epithelium as guardian of gut barrier integrity. Cellular Microbiology, 17(11), 1561-1569. http://doi.org/10.1111/cmi.12501

Zhu, X., Han, Y., Du, J., Liu, R., Jin, K., \& Yi, W. (2017). Microbiota-gut-brain axis and the central nervous system. Oncotarget, 8(32), 53829-53838. http://doi.org/10.18632/oncotarget.17754 